\title{
THINKING ABOUT LEARNING - INFERENCES FROM HOW WE SUPPORT CURRICULUM DESIGN
}

\author{
Gordon Stubley \\ Mechanical and Mechatronics Engineering, University of Waterloo \\ stubley@uwaterloo.ca
}

\begin{abstract}
Over the past 40 years there has been the development of well-structured workshops and educational movements to aid faculty members' teaching development. The present study is a reflective analysis of a set of five well-established teaching development initiatives with the hope of inferring how engineering educators collectively think about students' learning.

The content of the initiatives is organized into two broad groups: teaching strategies and characteristics and attributes of student learning. Analysis shows that all of these initiatives emphasize teaching strategies and put much less emphasis on developing understanding of student learning beyond emphasizing two broad general principles on student learning: teaching should be studentlearning centred, and learning for mastery requires purposeful active intellectual effort. However, beyond this there is little attention given to aligning teaching strategies with the cognitive mechanics occurring during learning. These initiatives seem to imply that faculty members should teach with a primary focus on student learning but that the details of the learning mechanics are of lesser concern in planning and delivering our courses.

This analysis leads to the open question: "Would a better understanding of the cognitive mechanisms involved in learning allow educators to better align teaching strategies with the needs of student learning and to adapt to evolving student characteristics?"
\end{abstract}

Keywords: teaching development workshops, studentcentred teaching, reflection, student learning mechanisms.

\section{INTRODUCTION}

Meta-cognition, defined as "Awareness and understanding of one's own thought processes, esp. regarded as having a role in directing those processes" [8], includes reflective practice, a focus of attention in this, [4] and [10], and other conference sessions. Our focus on reflection is based on the premise that developing our students' reflective skills will enhance the depth of their learning and promote attitudes conducive to life-long learning.
To what extent have we collectively applied reflective practice to our own learning of the skills and knowledge we use in our teaching? What would reflection imply about our collective understanding of student learning? The present study, a reflective analysis of the common workshops and movements that support engineering instructors' development as teachers, is aimed at providing insight into what we collectively understand about the learning processes of our students.

The analysis considers the following five teaching development initiatives:

- $\quad$ Instructional Skills Workshop (ISW) [2];

- $\quad$ Course Design Workshops [3], [5], and [9];

- $\quad$ CDIO (Conceive, Design, Implement, Operate) Initiative [1];

- $\quad$ Big Beacon [6]; and

- $\quad$ Carl Wieman Science Education Initiative [12].

In the next section a summary of each initiative including its purpose is presented along with a categorization of the initiative's content into two groupings: (i) teaching strategies and characteristics, and (ii) related attributes of student learning. This is followed by a discussion on the extent to which the mechanics of student learning is considered and the implications that follow from the observations. The paper concludes with some open questions on how our understanding of student learning processes might guide course and program curriculum development and design.

\section{TEACHING DEVELOPMENT INITIATIVES}

One of the significant developments in higher education over the past 40 years and especially over the past 20 years has been the development of a range of initiatives including well-structured workshops and educational movements to aid faculty members' efforts in course and program design. The five initiatives included in the present analysis have been used to varying degrees within Canadian engineering faculties to support and guide faculty members' teaching development. 


\subsection{Instructional Skills Workshop (ISW)}

Originally developed in British Columbia in the late 1970's, the Instructional Skills Workshop (ISW) [2] is now a well-established standardized 24-hour workshop that is offered at institutions across Canada and around the world. This workshop promotes a model of lesson design and delivery that promotes active student engagement (often referred to as the BOPPPS model). The recommended BOPPPS lesson design structure promotes an augmented introduction with clearly articulated intended student outcomes and pre-assessment of student understanding, a main body for delivery of content that involves active student engagement, and an augmented summary that includes post-assessment of student understanding.

The heart of the workshop is the mini-lesson cycle. Each participant gives three 10-minute mini-lessons over the workshop period. Each mini-lesson is video-captured and is followed by facilitated feedback that includes reflection, written and oral observations from the "students", and video review.

2.1.1. Teaching Strategies and Attributes. The central teaching strategy promoted in ISW is the BOPPPS lesson model design structure that includes a motivating introduction with stated learning outcomes, opportunity for active learning, and the use of pre- and post-assessment. Specific illustrative techniques for active learning activities are demonstrated through group lessons run by the workshop facilitators.

2.1.2. Attributes of Student Learning. An underlying premise of the ISW curriculum is that effective teaching for adult learners must be student-centred. Participants spend a significant portion of the workshop role playing as "students" for their colleagues' mini-lessons and provide written and oral feedback from a student learner perspective.

The theoretical foundation for the ISW curriculum is Kolb’s learning cycle [7], which recognizes that adult learners learn best through experiential education involving active experimentation, concrete experience, reflective observation, and abstract conceptualization. This theory is presented as an underlying premise for guiding effective teaching and example strategies and activities are suggested for each phase of the cycle.

\subsection{Course Design Workshops}

For over 20 years many institutions have offered intensive multi-day workshops to support course design [5] and [9]. In Canada many higher education institutions use a variation of the course re-design workshop developed at McGill University in the 1990's [9]. Typically, participants complete a draft syllabus that describes course goals, intended outcomes, activities, and assessments during the workshop and receive facilitated feedback on each element of the syllabus from other participants. Each participant is expected to be a content expert for their course and the workshop encourages course design to reflect disciplinary perspectives and norms [3].

2.2.1. Teaching Strategies and Attributes. The central concept that participants are encouraged to integrate into their teaching is course design alignment. The principle of course alignment suggests that focussing course content and activities to meet clearly stated intended course outcomes will promote effective learning. It also suggests that courses will be successful and well received if the learning activities prepare students for all assessments (in other words there are no surprises during assessment).

A second element of the workshop is that participants are challenged to be creative when expressing course outcomes and when considering potential learning activities. Concept mapping is typically used to prompt creative expression of course outcomes [9].

2.2.2. Attributes of Student Learning. Like ISW, student-centred teaching is an underlying premise of the workshop curriculum. Workshop activities to describe student characteristics are commonly included. Beyond this there is no attention given to the mechanics of the learning process.

\subsection{CDIO Initiative}

The Conceive, Design, Implement, Operate (CDIO) initiative presents a well-structured framework to guide engineering program curriculum design [1]. Growing out of MIT in the late 1990's the framework also promotes student-centred teaching and well-aligned program design. The distinguishing features of the framework are: (i) engineering program curriculum should prepare graduates to work effectively in all parts of the engineering design cycle (i.e. conception, detail design, implementation, and operation) and (ii) the engineering design cycle should be applied to the curriculum design challenge.

2.3.1. Teaching Strategies and Attributes. While the emphasis is on program design, with the focus on including implementation and operation there is an obvious expectation of significant hands-on and experiential project work in every CDIO designed curriculum. The framework recognizes that curriculum must promote student mastery of professional workplace skills such as communication and teamwork if meaningful student outcomes in technical knowledge are to be achieved through hands-on project work. Beyond these general expectations along with wellaligned curriculum design, the framework does not specify specific teaching strategies.

2.3.2. Attributes of Student Learning. There is an underlying premise in the CDIO initiative that an effective engineering curriculum will mimic and foster actual engineering workplace practice. While not explicitly stated, this premise is well supported by modern cognitive 
motivation theory [11] on the positive impacts of relevant authentic learning activities.

\subsection{Big Beacon Initiative}

The Big Beacon initiative [6] grew out of a collaboration between engineering education innovators at University of Illinois involved in re-inventing engineering curriculum and innovators at Olin College involved in implementing a new engineering program. From the above discussion it is clear that certain elements of engineering education, such as student-centred design, well-aligned curriculum, and relevant and authentic learning activities and assessments, are well-recognized as good practices that lead to meaningful student learning. The premise underlying the Big Beacon initiative is that a revolution in the collective engineering educator mindset is required before these established best practices and principles are universally adapted in our engineering programs.

2.4.1. Teaching Strategies and Attributes. The Big Beacon movement makes no attempt to promote particular teaching strategies. Instead the movement assumes that the best practices are known but significantly under-utilized. As a disrupter, the movement challenges engineering educators to emotionally connect to their disciplines and to their students.

2.4.2. Attributes of Student Learning. A unique feature of the Big Beacon manifesto [6] for revolution in engineering education is its recognition of the crucial role that emotion plays in education. In materials promoted by the Big Beacon movement, the importance of emotion and emotional connections is taken as self-evident.

\subsection{Carl Wieman Science Education Initiative}

Carl Wieman, Nobel Physics laureate, joined University of British Columbia in 2007 to lead a movement for redesigning the teaching of science in universities [12]. Following from his earlier work in science education at University of Colorado at Boulder, this initiative challenges science faculty to answer three questions using the scientific method and well-established evidence:

1. What should students learn?

2. What are students learning?

3. What instructional approaches improve student learning?

An essential component of this initiative is the use of postdoctoral fellows as teaching support fellows charged with supporting faculty members in incorporating wellestablished best practices into their teaching. This support has been crucial for helping established faculty incorporate new methods of teaching into their classroom practices and has also ensured that these post-doctoral fellows have a strong knowledge base for university level teaching should they move on to faculty positions.
2.5.1. Teaching Strategies and Attributes. Earlier work in physics education research had already established that instructional approaches involving active student experimentation and exploration are apt to improve student learning. As a consequence, while the initiative does not appear to be prescriptive beyond posing three open-ended questions, there is an implicit focus on the use of active learning activities.

2.5.2. Attributes of Student Learning. The first and second posed questions make it clear that this initiative, like the others discussed above, is student-centred. By measuring student outcomes (what are they learning) against intended student outcomes (what should they learn) the comparative effectiveness of instructional approaches can be inferred without knowing the details of the student learning process (in other words student learners are treated as "black-boxes" receiving instructional inputs and producing learning outcomes).

\section{DISSCUSION: GAP IN KNOWLEDGE OF MECHANICS OF LEARNING PROCESSES}

The 5 teaching development initiatives reviewed in the previous section are similar in that the focus on how we should teach dominates focus on how students learn. The three open-ended questions at the heart of the Wieman initiative clearly demonstrate that teaching development is guided by focussing on how we should teach. While specific teaching activities (i.e. in-class clicker quizzes, two-stage exams, etc.) are not emphasized there are several teaching principles that are encouraged as best-practices, including:

- Clearly defining and articulating intended student learning outcomes at lesson, course, and program levels (i.e. design should be student-centred);

- Aligning course learning activities (i.e. lectures, online content and activities, homework, quizzes, projects, etc.) with the intended outcomes;

- Formative and summative assessments should be consistent (aligned) with stated intended outcomes and related learning activities; and

- Learning activities should be designed to foster active student engagement.

As guiding best practices these principles are promoted because evidence suggests that they work well, which does make a powerful argument.

However, let us contrast this with the emphasis we take in preparing our students to be effective engineers capable of designing complex engineering systems. Consider the engineering practice of an internal combustion engine designer as an example of engineering practice applied to 
the design of a complex and multi-faceted engineering system. Do we expect engine designers to make meaningful design decisions strictly from observing the connections between inputs like fuel and air and outputs like power and emissions (i.e. by simply treating the engine as a "black-box")? No, we generally do not. An engineering education is expected to ensure that the engine designer has a sufficiently strong working knowledge of the principles of kinematics, deformable solid mechanics, fluid mechanics, thermodynamics, etc. to be able to infer how design changes will affect the mechanics of engine operation. In other words, engineering designers understand how engineering systems work.

Do we collectively understand how learning works? Looking at the 5 teaching development initiatives reviewed above, there is limited focus on how learning works beyond recognizing that:

- Deep (lasting) conceptual learning requires purposeful active intellectual effort [7];

- Motivation affects student engagement in learning activities; and

- Emotional connections are required to foster learning.

Clearly we have collectively made no serious attempt to learn the cognitive mechanics of learning and to use that knowledge in our teaching practice.

\section{SUMMARY}

Teaching engineering at the post-secondary education level is generally considered to be a complex and multifaceted challenge. We teach our students to understand the mechanics and operation of the engineering systems they will be designing. Why do we not learn the cognitive mechanics of student learning before designing our courses?

This analysis leaves us reflecting on whether a better understanding of the cognitive mechanisms involved in learning would allow us to better align teaching strategies with the needs of student learning and to adapt to evolving student characteristics.

\section{Acknowledgements}

The present study was prompted from and benefited from numerous discussions with the 2017 3M National Teaching Fellows cohort. In particular, discussions with Greg Evans, Alan Steele, and Glen Van Brummelen were very helpful. The support of 3M Canada and the Society for Teaching and Learning in Higher Education (STLHE) is gratefully acknowledged.

\section{References}

[1] Edward Crawley, Johan Malmqvist, Sören Östlund, and Doris Brodeur, Rethinking
Engineering Education: The CDIO Approach. New York, NY: Springer, 2010 (2nd ed.), 300 pp. \{ISBN: 978-1441-94260-9\}

[2] Russel Day \& the ISW International Advisory Committee, "Instructional Skills Workshop: From grassroots initiative to international perspectives” presented at Experiencing the Richness of the University Mosaic: from Diversity to Individuality., STLHE 2004, (Ottawa, ON; 16-19 June 2004), 6 pp., 2004. Available as of April 30, 2018 from https://www.iswnetwork.ca/wpcontent/uploads/2012/07/Hand5_ICED.pdf

[3] Janet Gail Donald. Learning to Think: Disciplinary Perspectives, San Francisco, California: Jossey-Bass, 2002, 330 pp. \{ISBN: 07879-1032-5\}

[4] Greg Evans, "A Windmills of Your Mind: Metacognition and Lifelong Learning” in Proc. 2018 Canadian Engineering Education Association Conference, Vancouver 2018, 5 pp.

[5] Richard Felder and Rebecca Brent, Teaching and Learning STEM: A Practical Guide, San Francisco, California: Jossey-Bass, 2016, 316 pp. \{ISBN: 9781118925812\}

[6] David Goldberg and Mark Somerville, A Whole New Engineer: The Coming Revolution in Engineering Education, Douglas, Michigan: ThreeJoy Associates, 2014, 264 pp. \{ISBN13: 978-0-9860800-0-5\}

[7] David Kolb, Experiential Learning: Experience as the Source of Learning and Development, Upper Saddle River, New Jersey: Pearson Education Inc., 2014 ( $2^{\text {nd }}$ ed.), 390 pp. \{ISBN13: 978-0-13-389240-6\}

[8] "metacognition, n.". OED Online. Oxford University Press. March 2018. Available as of May 02, 2018 from http://www.oed.com/view/Entry/245252?redirect edFrom=meta-cognition

[9] Alenoush Saroyan and Cheryl Amundsen (Eds.), Rethinking teaching in higher education: From a course design workshop to a faculty development framework, Sterling Virginia: Stylus Publishing, 2004, 272 pp. \{ISBN: 1-57922-046-0\}

[10]Alan Steele, "Developing Student MetaCognition in a Design Course”, in Proc. 2018 Canadian Engineering Education Association Conference, Vancouver 2018, 6 pp.

[11] Marilla Svinicki, Learning and Motivation in the Postsecondary Classroom, San Francisco California: Jossey-Boss, 2004, 263 pp. \{ISBN-13: 978-1-882982-59-2\}

[12] Carl Wieman, Improving How Universities Teach Science: Lessons from the Science Education Initiative, Cambridge, Massachusetts: Harvard University Press, 2017, 288 pp. \{ISBN: 9780674972070\} 